\section{Promoção de saúde: a convergência entre as propostas da vigilância da saúde e da escola cidadã}

\author{
Health promotion: convergence between \\ the principles of health surveillance \\ and socially responsible schools
}

\author{
Denise Aerts 1,2 \\ Gehysa Guimarães Alves 2,3 \\ Maria Walderez La Salvia ${ }^{4}$ \\ Claídes Abegg 1,5
}

\author{
1 Programa de Pós-Graduação \\ em Saúde Coletiva, \\ Universidade Luterana \\ do Brasil, Canoas, Brasil. \\ 2 Coordenadoria Geral \\ de Vigilância da Saúde, \\ Secretaria Municipal \\ de Saúde de Porto Alegre, \\ Porto Alegre, Brasil. \\ 3 Faculdade de Odontologia, \\ Universidade Luterana \\ do Brasil, Canoas, Brasil. \\ 4 Centro de Saúde Vila dos \\ Comerciários, Secretaria \\ Municipal de Saúde de Porto \\ Alegre, Porto Alegre, Brasil. \\ 5 Programa de Pós-Graduação \\ em Odontologia, Universidade \\ Federal do Rio Grande do \\ Sul, Porto Alegre, Brasil. \\ Correspondência \\ D. Aerts \\ Programa de Pós-Graduação \\ em Saúde Coletiva, \\ Universidade Luterana \\ do Brasil. \\ Av. Ganzo 238 \\ Rorto Alegre, RS \\ 90150-070, Brasil. \\ daerts@via-rs.net
}

\begin{abstract}
The authors discuss the convergence between health surveillance and socially responsible schools from a health promotion perspective in Porto Alegre, Rio Grande do Sul State, Brazil. The aim of health promotion strategies is to provide the population with the necessary means to improve their health. One of the explanatory paradigms for health surveillance is the social production of health, acknowledging the influence of living conditions on the population's health. The main thrust of schools that promote citizenship is social inclusion, achieved through education by recognizing the needs and possibilities of students and empowering citizens by raising awareness of their rights and duties. The convergence between health surveillance and socially responsible schools is demonstrated in four fields of health promotion: development of personal capacities by providing information and health education to empower people for healthier choices; strengthening of community action for better health; creation of healthfriendly public and private environments; and construction of healthy public policies, involving both government and nongovernmental organizations.
\end{abstract}

Health Promotion; Educational Models; Intersectorial Action
Este artigo discute a convergência das propostas do modelo de atenção da vigilância da saúde e da escola-cidadã desenvolvidas na Cidade de Porto Alegre, Rio Grande do Sul, Brasil, a partir da década de 90 . O texto está estruturado em quatro momentos. No primeiro, apresentase a discussão da proposta da promoção de saúde como vem sendo analisada nas últimas décadas. No segundo, discute-se a proposta da vigilância da saúde e seus elementos constitutivos na organização do sistema municipal de saúde. No terceiro, apresenta-se a proposta da escola-cidadã e suas características essenciais. Por último, discute-se a convergência teórica percebida pelas autoras, à luz de quatro dos cinco campos de ação da promoção da saúde.

\section{A promoção da saúde}

Em nenhum outro momento falou-se tanto em promoção da saúde como na década atual. Em 1986, na 1ạ Conferência Internacional de Promoção de Saúde, foi publicada a Carta de Ottawa, que ampliou o significado da concepção de promoção como conjunto de ações voltadas para a prevenção das doenças e riscos individuais para uma visão que considera a influência dos aspectos sociais, econômicos, políticos e culturais sobre as condições de vida e saúde 1 . Assim, a saúde é compreendida enquanto qualidade de vida e não apenas como ausên- 
cia de doença, determinando que os problemas de saúde sejam enfrentados valendo-se de ações intersetoriais, visto que extrapolam a responsabilidade exclusiva do setor saúde.

A Carta de Ottawa para Promoção de Saúde propõe cinco campos de ação para a promoção de saúde da coletividade: ambientes suportivos à saúde, facilitadores das escolhas saudáveis, objetivando promover saúde por intermédio da criação de condições de vida e trabalho que conduzam à saúde e ao bem-estar; construção de políticas públicas saudáveis, implicando abertura de espaços nas agendas dos formuladores de políticas públicas de todos os setores, tornando as escolhas saudáveis as mais fáceis; fortalecimento da ação comunitária, priorizando a participação de indivíduos e comunidades nas tomadas de decisões de questões que dizem respeito à sua saúde; desenvolvimento de habilidades pessoais, enfatizando a divulgação de informações sobre a saúde, educação para a saúde, nas escolas, universidades, locais de trabalho e qualquer espaço coletivo de forma a permitir que as pessoas tenham mais controle sobre sua saúde; e reorientação dos serviços de saúde, de um enfoque curativo para um enfoque preventivo de promoção de saúde, com a formação de profissionais capazes de acompanhar esta mudança 2,3.

Assim, a promoção da saúde passou a ser vista como uma estratégia mediadora entre pessoas e ambiente, visando aumentar a participação dos sujeitos e da coletividade na modificação dos determinantes do processo saúdedoença, como emprego, renda, educação, cultura, lazer e hábitos de vida. Desse modo, busca proporcionar aos povos meios necessários para melhorar sua saúde, cabendo ao estado a responsabilidade de reduzir as diferenças, assegurar a igualdade de oportunidades e promover os meios que permitam a todos desenvolver um melhor controle sobre ela 4 .

A partir da Conferência de Ottawa, em 1986, vários outros encontros e conferências têm sido organizados no intuito de aprofundar a discussão da promoção da saúde, incluindo estratégias importantes como políticas públicas saudáveis (http://www.who.int//hpr/NPH/ docs/adelaide-recommendations.pdf, acessado em 05/Jan/2004), meio ambiente favorável à saúde (http:/ / www.who.int/hpr/NPH/sundsval_ statement.pdf, acessado em 05/Jan/2004) e desenvolvimento sustentável (http://www.who. int/violence_injury_prevention/media/em/ 633.pdf, acessado em 05/Jan/2004). As discussões sobre a promoção colocaram em relevo a importância do entorno, uma vez que pode ser um grande obstáculo para a saúde (violência, desemprego, poluição) ou proteger a saúde dos indivíduos (proteção ambiental, inclusão social) 5 .

A IV Conferência Internacional de Promoção da Saúde, em Jacarta - 1997, procurou avançar nas discussões dos fatores que impedem a concretização do novo conceito de saúde e coloca como principal ameaça para sua execução o aumento da pobreza. A Carta de Jacarta propõe novas ações frente a essa ameaça: a cooperação internacional e a criação de novas parcerias (http://www.who.int/hpr/NPH/docs/jakarta _declaration_portuguese.pdf, acessado em 05/ Jan/2004).

O conceito de promoção da saúde traz como princípios norteadores um conjunto de valores éticos, como a vida, a solidariedade, a eqüidade e a cidadania, e uma série de estratégias que visam concretizar a cooperação e parcerias 2 . A importância dessas, quer sejam em nível internacional ou local, entre diferentes atores e instituições, entre o público e o privado, entre distintos setores, é inquestionável e determinante do êxito da promoção da qualidade de vida das populações.

O diálogo intersetorial é difícil, pois é preciso respeitar a visão do outro e sua contribuição para a construção de soluções para os problemas levantados, entretanto, pode ser uma importante estratégia de reconstrução da esfera pública (http://www.cedaps.org.br/opniao_ construcao.htm, acessado em 05/Jan/2004). Além disso, a colaboração de vários setores, visando a um objetivo único, oferece uma série de vantagens: aumentar o conhecimento e a compreensão entre setores, diminuindo as rivalidades e esclarecendo o papel de cada um; assegurar o planejamento de ações de saúde baseadas no conhecimento ampliado das necessidades da comunidade; e garantir que as informações sobre saúde recebidas pelo público sejam uniformizadas 6 .

A intersetorialidade pode ser definida como a articulação de saberes e experiências na identificação participativa de problemas coletivos, nas decisões integradas sobre políticas e investimentos, com o objetivo de obter retornos sociais na perspectiva da inclusão social e superação do modelo de desenvolvimento sócio-econômico atualmente vigente 7 .

O cerne da ação intersetorial localiza-se na gestão pública de um território bem definido. Nesse sentido, a cidade é um espaço privilegia- 
do que pode ser viabilizado politicamente, mediante um novo olhar e um novo agir sobre a realidade, definindo democraticamente os problemas prioritários, cuja redução ou controle necessita de habilidades e compromissos de diversos setores. A implementação da intersetorialidade deve se dar por meio de um planejamento que envolva todos os setores, para que todos tenham claras as suas responsabilidades e funções, conhecendo as interfaces necessárias (www.redeunida.org.br:8080 \forum \salas \ 3, acessado em 05/Jan/2004).

Idealmente, a coordenação dessas ações ficará a cargo do prefeito municipal, já que é a pessoa capaz de fazer a articulação entre os diversos setores governamentais. Essa liderança garante o desencadeamento de ações intersetoriais necessárias ao desenvolvimento de uma cidade saudável, onde os atores sociais orientam suas ações a fim de transformar a cidade em um espaço de produção social da saúde, construindo uma melhor qualidade de vida para seus moradores. Nesse sentido, a saúde é colocada como objeto de todas as políticas públicas.

Contudo, a abordagem intersetorial extrapola a esfera do próprio governo. A promoção da saúde deve ser assumida como responsabilidade de todos os setores, visto que os governos sozinhos são incapazes de responderem pelas demandas sociais que determinam a saúde. Em função disso, exige o comprometimento de toda a sociedade. No entanto, o poder executivo municipal é responsável por conduzir o processo de viabilização de uma cidade saudável e o setor saúde por desencadear a discussão e a inclusão dos outros setores. Essa tarefa exige uma ação coordenada de todos os implicados: governo, organizações não governamentais, meios de comunicação e população. Sem isso, é difícil viabilizar uma sociedade mais fraterna e humana 8 (http://www.cedaps.org.br/ opniao_construcao.htm, acessado em 05/Jan/ 2004).

Na estratégia intersetorial, a saúde e a educação devem poder ser pensadas de forma mais integradora. Em maio de 2001, foi assinada uma portaria interministerial que elaborou os Parâmetros Curriculares Nacionais em Ação. Esses parâmetros apontam para a construção de uma nova cultura em que a saúde e a educação trabalhem com temas transversais - pluralidade cultural, ética, orientação sexual, cidadania, meio ambiente, trabalho, consumo com base em situações concretas vivenciadas no cotidiano das populações. Assim, o conhecimento deve ser tratado como algo que é construído e apropriado, fruto da interação e cooperação entre sujeitos que são diferentes 9 . Os novos parâmetros curriculares apontam para a necessidade de planejar o trabalho institucional levando em consideração as especificidades locais, regionais e culturais.

O grande desafio, hoje, consiste em desenvolver uma sociedade mais saudável, estimulando o planejamento de políticas públicas capazes de promover a saúde, investindo em pesquisas e ações que incidam na melhoria da qualidade de vida das populações e estimulando a participação popular.

Em Porto Alegre, Rio Grande do Sul, a estratégia da promoção da saúde concretiza-se de diferentes formas na dependência da especificidade de cada área: na Polícia, com a proposta de Polícia Social, Democrática ou Comunitária; na Educação, com a Escola Cidadã; e na Saúde, com a Vigilância da Saúde. No entanto, essas propostas tiveram origem dentro dos diferentes setores, sem que se perceba uma política municipal articuladora de tais iniciativas. No que diz respeito à Vigilância da Saúde e à Escola Cidadã, percebe-se a convergência teórica das duas propostas, embora ela não tenha sido planejada nos respectivos setores.

\section{O modelo da vigilância da saúde}

Tomou-se como referência para o entendimento de modelo ou modo de atenção, três definições de autores brasileiros. A primeira define-o como um conceito capaz de articular o técnico e o político, incorporando contribuições sociais, culturais, políticas, clínicas, éticas, jurídicas, administrativas, dentre outras 10 . A segunda, de Carvalho \& Ribeiro 11, define-o como a maneira como são organizadas e combinadas as diferentes ações de intervenção no processo saúde e doença; e a terceira, proposta por Paim 12, como as combinações tecnológicas utilizadas pela organização dos serviços de saúde em determinados espaços-populações, incluindo ações sobre o ambiente, grupos populacionais, equipamentos comunitários e usuários de diferentes unidades prestadoras de serviços com distinta complexidade. Assim, entende-se vigilância da saúde como um modelo de atenção.

Os modelos de atenção à saúde que mais se destacaram ao longo da história brasileira foram o sanitarista, na primeira metade do século XX, o médico-assistencial privatista, ainda presente nos dias de hoje, e os alternativos.

O modelo sanitarista, por organizar suas atividades fundamentalmente na forma de campanhas e programas dirigidos a problemas específicos, como dengue, tuberculose e imunizações, dificulta o desenvolvimento de ativi- 
dades rotineiras das equipes de saúde e, ao atuar de forma paternalista, desresponsabiliza a população pela busca de sua própria saúde.

O modelo médico-assistencial tem como principal característica ser voltado para a demanda espontânea, ou seja, aos indivíduos que procuram os serviços de saúde. Conseqüentemente, aqueles que não percebem com seus problemas ou desconhecem as medidas preventivas disponíveis não se beneficiam com os serviços oferecidos. Uma das maiores críticas a esse modelo consiste em sua incapacidade de impactar significativamente os níveis de saúde da coletividade 12 .

Os modelos médico-assistencial e sanitarista não conseguiram responder plenamente às necessidades da população. Com isso, observou-se, especialmente a partir da década de 80, o surgimento de propostas alternativas, buscando concretizar os princípios e diretrizes da Constituição Brasileira: acesso universal, hierarquização, descentralização e participação popular.

O modelo da vigilância da saúde tem como objetivo instituir um novo modo de relação com a população sob responsabilidade dos serviços de saúde, em que não só os indivíduos devem ser vistos em sua integralidade como também $o$ atendimento deve ser pautado no acolhimento e respeito pelo outro. "A vigilância da saúde é uma nova forma de resposta social organizada aos problemas de saúde, referenciada pelo conceito positivo de saúde e pelo paradigma da produção social da saúde. Por conseguinte, essa prática tem de, a um tempo, recompor o fracionamento do espaço coletivo de expressão da doença na sociedade, articular as estratégias de intervenção individual e coletiva e atuar sobre todos os nós críticos de um problema de saúde, com base em um saber interdisciplinar e em um fazer intersetorial" 13 (p. 243-4).

Portanto, a vigilância da saúde utiliza como paradigma explicativo, a determinação social do processo saúde-doença, reconhecendo a importância das condições de vida sobre as condições de saúde da população, indo buscar na promoção estratégias de intervenção na realidade. Tem como características: intervenção sobre problemas de saúde; ênfase em problemas que requerem atenção e acompanhamento contínuo; operacionalização do conceito de risco; articulação entre as ações de promoção, prevenção, recuperação e reabilitação; atuação intersetorial e ações sobre o território 14.

A dimensão de território é inerente à vigilância da saúde. Território é um espaço em permanente construção e significa a área geográfica e tudo o que existe dentro dela. É o espaço de vida, conflitos, interesses, projetos e sonhos, ou seja, a forma como as pessoas vivem, se organizam, adoecem e morrem. É esse território que deverá ser "esquadrinhado" de modo a proporcionar o conhecimento da realidade de saúde que é permeada pela dinâmica das relações sociais, econômicas, políticas e culturais. Além disso, deve-se dar ênfase aos problemas, identificando a diferença entre o que é e o que deveria ser, de acordo com os valores desejáveis do ponto de vista dos atores sociais. A pactuação entre as necessidades sentidas pela população e os problemas identificados pela equipe de saúde deve subsidiar as ações de planejamento e programação dos serviços de saúde. Trabalhar com problemas de saúde significa entender a representação social das necessidades sanitárias, derivadas das condições de vida 13 .

Logo, esse modelo de atenção tem como sujeito a equipe de saúde e a população, elegendo como objeto de trabalho os danos, riscos, necessidades e determinantes dos modos de vida e saúde. Sua prática deve transcender os espaços institucionais do sistema de saúde, ampliando-se para órgãos governamentais ou não, envolvendo diversos grupos sociais. No momento em que a equipe de saúde sai a "campo" para conhecer o seu território, interage com a população e estabelece outra relação com ela.

Esse novo jeito de fazer saúde exige que os profissionais desempenhem o papel de educadores, sendo capazes de auxiliar a população sob sua responsabilidade a tornar-se agente na promoção e proteção de sua saúde e da saúde da cidade. Para tanto, devem desencadear um processo de aprendizagem, no qual o ensinar e o aprender possam se efetivar de uma forma relacional e não hierárquica. Nesse sentido, as pessoas devem ser o elemento central de todas as ações (primazia das pessoas), tendo mais controle sobre suas próprias vidas (apoderamento), sendo capazes de identificar fatores que afetam sua saúde e, com isso, exercendo maior controle sobre eles (viabilização) (Hills $\mathrm{M}$, em documento distribuído na Oficina para professores de promoção da saúde, realizada durante o VI Congresso Brasileiro de Saúde Coletiva em Salvador, 2000).

Em Porto Alegre, esse modelo de atenção vem sendo delineado desde o início da década de 90, com a reorganização da rede básica, a municipalização plena da gestão, culminando com a completa territorialização do município, onde cada serviço de saúde passou a ser responsável pela população moradora em sua área, estando referida a uma gerência distrital. Na III Conferência Municipal de Saúde, em maio de 2000, foi discutida a concepção de sa- 
úde em sua perspectiva de "qualidade de vida", podendo melhorar ou piorar conforme as ações desencadeadas sobre os fatores que lhes determinam. O modelo de atenção da vigilância da saúde foi reafirmado, embasado por esse conceito ampliado de saúde, sendo reconhecido o Programa Saúde da Família como uma estratégia para a viabilização desse modelo 15 .

No ano de 2002, ocorreu a necessária compatibilização dos territórios dos distritos sanitários e das regiões do orçamento participativo, territórios de planejamento, gestão e participação da população no governo municipal.

Hoje, o município conta com cinqüenta serviços básicos de saúde e sessenta e duas (62) equipes do Programa Saúde da Família (PSF). Contudo, com o convênio assinado com o governo federal para a execução do Projeto Municipal de Expansão da Saúde da Família os serviços básicos passarão a funcionar dentro da lógica do PSF 16. Com isso, atuar na vigilância da saúde passa a ser a lógica que deverá nortear todos os serviços básicos de saúde nos próximos anos.

\section{A proposta da escola cidadã}

A escola, espaço socialmente reconhecido para desenvolver o ato pedagógico, é uma instituição em que o ser humano passa longa e importante etapa de sua vida. Por sua missão educativa ser complementar à missão da família, a escola contribui na construção de valores pessoais e dos significados atribuídos a objetos e situações, entre eles a saúde.

Tomando-se a educação como um processo dialógico, problematizador e inclusivo, que visa à construção da consciência crítica sobre o ser e o estar no mundo, observam-se várias tentativas de mudanças pedagógicas em diversas cidades do Brasil.

A escola saudável é aquela que possui um ambiente solidário e propício ao aprendizado, por isso ela deve estar engajada no desenvolvimento de políticas públicas saudáveis e na estimulação da criação de entornos favorecedores à saúde, na aprendizagem de comportamentos que permitam a proteção do meio ambiente, na conservação de recursos naturais e na implicação cada vez maior da população em projetos de promoção da saúde.

Em Porto Alegre, a proposta pedagógica da escola cidadã, instituída na Secretaria Municipal de Educação em 1995, é um desdobramento do projeto municipal Cidade Constituinte, em que estão delineadas as políticas desejadas para a cidade 17 .
Essa proposta surgiu como resposta à burocratização do ensino e sua ineficiência, pois o sistema oficial de ensino não conseguia garantir a qualidade e a inclusão social, uma vez que trabalhava os conteúdos completamente descolados da realidade vivenciada pelos alunos e suas famílias. A escola cidadã ou democrática tem como eixos norteadores a integração entre educação e cultura, escola e comunidade; a democratização das relações de poder dentro da escola; o enfrentamento da repetência e da avaliação; a visão interdisciplinar; e a formação permanente dos educadores (http://www. paulofreire.org/pf/reflexao.htm, acessado em 05/Jan/2004).

A escola contribui na construção de valores pessoais, crenças, conceitos e maneiras de conhecer o mundo e interfere diretamente na produção social da saúde, na medida em que atua na exclusão ou na inclusão social. Reconhecendo isso, a escola cidadã tem como diretriz central a inclusão social e contribui para a promoção da saúde na proporção em que busca formar sujeitos críticos, criativos e conscientes e que proporciona a aprendizagem de acordo com as necessidades e possibilidades dos alunos 18 .

Todavia, para que as aprendizagens sejam significativas, é necessário construir um processo dialógico no qual aprender e ensinar possam se efetivar em um clima agradável e prazeroso e, com isso, contribuir para a saúde física e mental de alunos, professores e funcionários.

A escola inclusiva, reafirmada a partir da Declaração de Salamanca, na Conferência Mundial de Educação Especial, em 1994, garante o direito à educação independentemente de diferenças individuais (http://paidos.rediris.es/ genysi/recursos/doc/leyes/dec_sal.htm, acessado em 05/Jan/2004). A inclusão baseia-se na valorização da diversidade humana, no direito de pertencimento e na busca de soluções para o desafio da presença do diferente.

Em Porto Alegre, os projetos político-pedagógicos das escolas expressavam a necessidade de tempos e espaços escolares não excludentes e pautados pela necessidade concreta e histórica dos alunos e suas famílias. Valendo-se dessa discussão entre Conselho Municipal de Educação, Secretaria Municipal de Educação e Rede Municipal de Ensino, foi proposta a escola por ciclos de formação 19 .

Essa escola abre a possibilidade de o aluno aprender os conteúdos durante um tempo que pode ser maior que um ano. Assim sendo, houve a mudança curricular do regime seriado para os ciclos de formação, cuja estrutura é de 
três ciclos com três anos cada, totalizando nove anos de ensino fundamental.

Esse tipo de organização alicerça-se numa visão de currículo processual, considerando as realidades vividas pelos alunos, e procura construir um processo educativo interativo. Tal mudança não se limita à discussão de conteúdos e carga horária, ela busca a inter-relação entre as áreas do conhecimento e entre essas e a sociedade 19. Com base nessa visão, o investimento pedagógico privilegia o que o aluno já sabe e as possibilidades de continuar avançando no processo de aprendizagem.

O ciclo é uma estratégia de enfrentamento ao fracasso escolar, na medida em que leva em conta as características dos alunos em suas diferentes faixas etárias e realidades sócio-culturais. Como esses ciclos não terminam no final de um ano, oferecem a possibilidade aos alunos de recuperarem, no ano seguinte, os conteúdos não apreendidos.

A realidade em que vivem os alunos, suas características sócio-culturais, seus valores e crenças são investigados por intermédio de uma pesquisa sócio-antropológica, realizada periodicamente com a comunidade, que busca conhecer como e onde vivem os alunos e suas famílias e quais são suas necessidades, problemas e expectativas. O conhecimento gerado com a pesquisa subsidia a escolha e a organização dos conteúdos e atividades pedagógicas 20.

Como o currículo é organizado, fundamentando-se nessa realidade, discute temas transversais e atuais que contribuem para um ambiente mais saudável. Ademais, trabalha pela inclusão social, estimulando a participação da população nas discussões escolares e possibilita aos seus alunos uma maior participação na sociedade a partir da experiência de cidadania vivida na escola.

A proposta prevê ainda o acompanhamento sistemático do aluno e, ao invés de esperar que ele(a) reprove, os professores devem atendê-los ao longo do ano, trabalhando o reforço do conteúdo e o acolhimento dos alunos. Com essas medidas, muitos alunos que estavam "predestinados" ao insucesso passam a ter a possibilidade de seguir os seus estudos e aprender os conteúdos 21.

A escola promove a saúde na proporção em que consegue assegurar condições saudáveis tanto no espaço da sala de aula como dentro do espaço escolar. Condições saudáveis promovem um ambiente propício à aprendizagem, buscam estimular as relações entre as pessoas, promovem a participação e a criatividade do aluno e entendem que a auto-estima e a autonomia são aspectos fundamentais para a promoção da saúde 18 .

\section{Convergências entre escola cidadã e vigilância da saúde}

Ao se analisar a proposta da vigilância da saúde e a da escola cidadã, percebe-se que ambas estão pautadas no referencial teórico da promoção de saúde, ocorrendo uma convergência conceitual explicitada em quatro dos cinco campos de ação da promoção de saúde.

Desenvolvimento de habilidades pessoais, por meio de informações e educação em saúde, visando proporcionar escolhas mais saudáveis

A escola cidadã contribui para a promoção da saúde ao mesmo tempo em que busca formar cidadãos conscientes de seu estar "no" e "com" o mundo, refletindo criticamente sobre sua vida e caminhos para construí-la de uma forma saudável. Tem como ideal um ensino voltado para a realidade do aluno e o desenvolvimento de sua autonomia, intentando transformar a escola num espaço em que haja desejo e alegria na construção do conhecimento.

A vigilância da saúde privilegia, entre suas ações, a educação em saúde, entendida como uma prática social que cria oportunidade aos cidadãos de identificação de seus problemas de saúde e das situações que os determinam, incentivando a procura de soluções coletivas. Tem o papel de potencializar as capacidades dos sujeitos e dos grupos populacionais para incidirem positivamente em suas trajetórias de vida, o que implica intervir nas relações sociais que constroem ao longo do tempo.

A escola e o serviço de saúde atuam na vida cotidiana, discutindo valores, crenças, mitos, hábitos e estilos de vida em momentos em que os indivíduos estão mais suscetíveis à reflexão sobre esses aspectos. Nessa perspectiva, é de especial importância a atuação desses setores junto a crianças e adolescentes, sujeitos em desenvolvimento, na construção de projetos saudáveis de vida. Um exemplo disso, em relação a meninas, é a questão da gestação na adolescência. Para as mais pobres, muitas vezes, a maternidade coloca-se como um projeto de vida, sendo a única alternativa ao desenvolvimento profissional obstaculizado pela falta de caminhos. Para os meninos, acontece situação semelhante: a afirmação da identidade social pode se dar pela vinculação a grupos que se utilizam de condutas anti-sociais, como o roubo ou uso de drogas lícitas e ilícitas, colocando-os no caminho da violência. Em tais situações, a saúde e a educação devem atuar conjuntamente, contribuindo para a construção de projetos alternativos de vida. 
Fortalecimento da ação comunitária na busca da melhoria das condições de saúde

A escola cidadã e a vigilância da saúde propõem o reconhecimento do território sob responsabilidade dos trabalhadores de cada setor como estratégia para o planejamento de suas ações. Esse processo de desvelamento da realidade, chamado de pesquisa sócio-antropológica, na escola, e de territorialização, na saúde, permite uma aproximação com a população, sua cultura e o reforço à participação popular. Nessa perspectiva, território é entendido como um espaço em permanente construção, permeado por uma dinâmica social em que pessoas interagem entre si e com as instituições que ali atuam, e não apenas como um espaço geográfico 13 .

Na escola, os conteúdos trabalhados estão permeados por valores e crenças dos professores em relação a diferentes aspectos. Na saúde, a atuação dos profissionais também é influenciada por sua percepção do mundo, muitas vezes distanciada da realidade em que vivem os grupos populacionais por eles atendidos. Daí a importância do reconhecimento da cultura local e da pactuação de necessidades e problemas identificados pela população e técnicos e de ações a serem desenvolvidas. É no reconhecimento dos diferentes saberes e culturas que se viabiliza a participação popular.

A formalização de espaços para essa participação existe tanto nas propostas da vigilância da saúde como na escola cidadã, via conselhos municipais de saúde, conselhos escolares, conferências locais e nacionais e outros fóruns instituídos para a discussão de questões pertinentes às duas áreas. No entanto, sua efetivação precisa ser construída cotidianamente por profissionais e população.

\section{Criação de ambientes favoráveis à saúde}

Para o processo de transformação da vida, é fundamental a compreensão da determinação do social, político, cultural e do meio físico sobre a saúde de indivíduos e coletividades; porém, para viabilizar essa compreensão, é preciso discutir de que forma estilos, hábitos e condições de vida e trabalho influenciam as formas de adoecer, morrer e receber os cuidados de saúde. Ainda que a Constituição garanta os mesmos direitos a todos os cidadãos, as desigualdades na qualidade de vida fazem com que seja imperioso perseguir a eqüidade, atuando sobre as iniqüidades com ações voltadas para os determinantes dos problemas de saúde 22 .

A proposta da escola cidadã propicia a identificação de temas transversais, uma vez que prevê, semelhante à vigilância da saúde, o reconhecimento do território, a saída dos professores da escola, com o objetivo de conhecer a realidade dos alunos e, a partir daí, organizar o conteúdo de forma a que ele não seja excludente e preconceituoso. Utilizando como tema gerador do ensino os conteúdos levantados nesse trabalho de campo, mediante a identificação de problemas e necessidades dos grupos populacionais, é possível desencadear um aprendizado mais concreto, voltado para a qualidade de vida e o sentido de cidadania.

Tanto no enfoque da vigilância da saúde como na proposta da escola cidadã em Porto Alegre, verifica-se um investimento com intuito de oferecer a seus diferentes usuários informações que os instrumentalizem na busca de ambientes de vida e de trabalho saudáveis. Essas informações visam promover a saúde, prevenir o adoecimento e reduzir as situações que vulnerabilizam os indivíduos e os grupos populacionais.

A proposta do Ministério da Educação e Cultura 23 acerca de temas transversais concretizase na escola cidadã com a discussão sobre os determinantes da qualidade de vida e com a participação das famílias na vida escolar. Nos serviços de saúde, a transversalidade se faz presente com o desenvolvimento de ações de vigilância epidemiológica, sanitária e ambiental e ações de atenção e educação em saúde, voltadas para indivíduos e coletividade.

Ao se pensar na promoção da saúde via criação de ambientes saudáveis, é necessário incluir, além do já mencionado, o meio físico e a estrutura da organização, da administração e da gestão das instituições públicas ${ }^{5}$. Tanto na saúde como na educação, os conselhos locais e municipais configuram-se em espaços potencializadores de uma maior participação da sociedade na gestão dessas instituições.

\section{Construção de políticas públicas saudáveis, envolvendo órgãos governamentais e não governamentais}

A construção de políticas públicas saudáveis requer a atuação na perspectiva da intersetorialidade, reconhecendo que a saúde é determinada por processos externos a ela. Assim, a intersetorialidade deve ser entendida como um processo articulado e integrado de formulação e implementação de políticas públicas, com a integração de estruturas, recursos e processos organizacionais, sendo as responsabilidades partilhadas pelos setores governamentais, não governamentais e pela sociedade civil ${ }^{9}$. Além disso, possibilita aos envolvidos a aprendizagem do conviver com o outro, o respeito pelas 
diferenças e a percepção de que a multiplicidade de olhares contribui para o planejamento de ações mais integralizantes e totalizadoras.

A escola cidadã busca a inter-relação com outras instituições para a elaboração e o desenvolvimento de suas atividades educativas, proporcionando a pais, alunos, professores e funcionários a vivência de experiências intersetoriais. Essas vivências, problematizadas em sala de aula e em outros espaços escolares, propiciam a identificação da ação intersetorial como estratégia central no enfrentamento das iniqüidades. Na vigilância da saúde, a intersetorialidade se faz presente em praticamente todas as ações voltadas à coletividade, mediante problemas e necessidades identificadas pela própria população.

\section{Considerações finais}

O presente artigo coloca em evidência a inequívoca convergência teórica do modelo de atenção da vigilância da saúde e da proposta da escola cidadã, pois ambas se embasam na estratégia da promoção da saúde.

Ao organizar-se por ciclos, a escola cidadã respeita o aprendizado do aluno, que também ocorre por ciclos. Com isso, evita a exclusão e a repetência escolar, uma vez que os professores dispensam uma maior atenção aos processos individuais de aprendizagem, possibilitando que o aluno vá construindo suas aprendizagens ao longo do ciclo.

A escola cidadã é uma escola promotora da saúde; porém, todas as escolas podem e devem trabalhar nessa perspectiva. Para tanto, é necessário aprofundar a reflexão com os alunos sobre a saúde enquanto resultante do processo social, dado que, muitas vezes, é abordada apenas como ausência de doença, em uma perspectiva de responsabilidade individual, ou co- mo o completo bem estar biopsicossocial, situação essa impossível de ser alcançada 18. Nesse sentido, os profissionais da saúde podem colaborar com a escola ao compartilhar conhecimentos e práticas que auxiliem o entendimento da saúde como direito do cidadão, instrumentalizando-a acerca das questões sociais mais abrangentes que determinam o "estar ou não saudável".

As atividades em sala de aula e na escola devem incluir a saúde como tema gerador, podendo as diferentes disciplinas articularem seus conteúdos programáticos com as condições de vida da população, possibilitando a reconstrução do conceito de saúde.

A educação e a saúde têm papel fundamental na mobilização de redes sociais, envolvendo setores governamentais, não governamentais e sociedade para o enfrentamento da exclusão social, promovendo a qualidade de vida e a cidadania. Isso requer o reconhecimento da realidade e da cultura local, uma sociedade civil organizada e participativa e relações horizontais e ações complementares entre os participantes (http://www.upeg.br/nupes/intersetor. htm, acessado em 05/Jan/2004).

No entanto, o que se vê na prática é que nem sempre os serviços de saúde e a escola conseguem concretizar o que suas propostas teóricas prevêem: seu planejamento com base no reconhecimento das necessidades locais, a contribuição para uma prática de inclusão social que auxilie a diminuir as iniqüidades e o estímulo e fortalecimento da participação popular.

Frente às propostas setoriais desenvolvidas na cidade de Porto Alegre, em especial a Vigilância da Saúde e a Escola Cidadã, acredita-se ser fundamental que o poder público municipal assuma seu papel de gestor, articulando as diferentes estratégias implementadas e construindo políticas públicas saudáveis intersetoriais, embasadas na promoção da saúde.

\section{Resumo}

Os autores discutem a convergência entre o modelo de atenção da vigilância da saúde e a proposta da escolacidadã, com base na promoção da saúde, em Porto Alegre, Rio Grande do Sul, Brasil. A vigilância da saúde tem como paradigma explicativo a produção social da saúde, reconhecendo a importância das condições de vida sobre a saúde da população. A escola cidadã tem como diretriz central a inclusão social, proporcionando a aprendizagem de acordo com as necessidades $e$ possibilidades dos alunos e a formação de cidadãos conscientes de seus direitos e deveres. A estratégia da promoção da saúde busca proporcionar aos povos meios necessários para melhorar sua saúde. A convergên-

cia entre o modelo de atenção da vigilância da saúde e a proposta da escola cidadã se explicita em quatro campos de ação da promoção da saúde: o desenvolvimento de habilidades pessoais, por meio de informações e educação em saúde, visando proporcionar escolhas mais saudáveis; o fortalecimento da ação comunitária na busca da melhoria das condições de saúde; a criação de ambientes favoráveis à saúde, públicos e privados; $a$ construção de políticas públicas saudáveis, envolvendo órgãos governamentais e não governamentais.

Promoção da Saúde; Modelos Educacionais; Ação Intersetorial 


\section{Colaboradores}

Todos os autores participaram desde a revisão de literatura e análise de material documental até a redação final do artigo.

\section{Referências}

1. World Health Organization. The Ottawa charter for health promotion. Ottawa: Canadian Public Health Association; 1986.

2. Buss PM, Ferreira JR. Promoção da saúde e a saúde pública: contribuição para o debate entre as escolas de saúde pública da América Latina. Rio de Janeiro: Escola Nacional de Saúde Pública, Fundação Oswaldo Cruz; 1998.

3. Moyses S, Watt R. Promoção de saúde bucal - definições. In: Buischi YP, organizador. Promoção de saúde bucal na clínica odontológica. São Paulo: Editora Artes Médicas; 2000. p. 1-21.

4. Buss PM. Promoção da saúde e qualidade de vida. Ciênc Saúde Coletiva 2000; 5:163-77.

5. Gentile M. Promoção da saúde e as cartas: de intenções escritas à operacionalização de ações. In: Gentile M, organizador. Promoção da saúde e município saudável. São Paulo: Editora Vivere; 2001. p. 55-93.

6. Naidoo J, Wills J. Health promotion, foundations for practice. London: Baillière Tindall; 1996.

7. Junqueira LAP, Inojosa RM. O movimento do setor saúde e o desafio da intersetorialidade. São Paulo: Edições Fundap; 1996. (Cadernos Fundap 21).

8. Dalmaso ASW, Nemes Filho A. Promoção à saúde Programa saúde da família.http://ids-saude.uol. com.br/psf/medicina/temal/texto3_definicao.asp (acessado em 05/Jan/2004).

9. Projeto Promoção da Saúde, Secretaria de Políticas de Saúde, Ministério da Saúde. A promoção da saúde no contexto escolar. Rev Saúde Pública 2002; 36:533-5.

10. Campos GWS. Sobre la reforma de los modelos de atención: un modo mutante de hacer salud. In: Eibenschutz C, organizador. Política de saúde: o público e o privado. Rio de Janeiro: Editora Fiocuz; 1995. p. 95-8.

11. Carvalho AI, Ribeiro JM. Modelos de atenção à saúde. In: Carvalho AI, Goulart FA, Ribeiro JM, Malachias $\mathrm{CH}$, organizadores. Gestão em saúde unidade II: planejamento da atenção à saúde. Rio de Janeiro: Editora Fiocruz/Brasília: Universidade de Brasília; 1998. p. 37-53.

12. Paim JS. A reforma sanitária e os modelos assis tenciais. In: Rouquayrol MZ, Almeida Filho N, organizadores. Epidemiologia \& saúde. Rio de Janeiro: MEDSI; 1998. p. 473-87.

13. Mendes EV. Uma agenda para a saúde. São Paulo: Editora Hucitec; 1996.

14. Teixeira CF, Paim JS, Vilasbôas NA. SUS: modelos assistenciais e vigilância da saúde. Inf Epidemiol SUS 1998; 8:7-26.
15. Secretaria Municipal da Saúde. III Conferência Municipal de Saúde: aprofundando o controle social. Cadernos de resoluções. Porto Alegre: Secretaria Municipal da Saúde; 2000.

16. Secretaria Municipal da Saúde. Projeto municipal de expansão da saúde da família. Porto Alegre: Secretaria Municipal da Saúde; 2003.

17. Susin MOK. Educação, esperança e diálogo. In Gorodicht C, organizador. Trajetória por uma educação cidadã. Porto Alegre: Conselho Municipal de Educação; 2002. p. 59-64.

18. La Salvia MW. Representação de saúde e prática pedagógica: o cotidiano de uma escola por ciclos [Dissertação de Mestrado]. Porto Alegre: Faculdade de Educação, Universidade Federal do Rio Grande do Sul; 2001.

19. Secretaria Municipal de Educação de Porto Alegre. Ciclos de formação: proposta político-pedagógica da escola-cidadã. Porto Alegre: Secretaria Municipal de Educação de Porto Alegre; 1996. (Cadernos Pedagógicos 9).

20. Secretaria Municipal de Educação de Porto Alegre. Fazendo diferença: a educação especial na rede municipal de ensino de Porto Alegre. Porto Alegre: Secretaria Municipal de Educação de Porto Alegre; 2000. (Cadernos Pedagógicos 20).

21. Azevedo JC. O processo de democratização e o Conselho Municipal de Educação em Porto Alegre. In: Gorodith C, organizador. Trajetória por uma educação cidadã. Porto Alegre: Conselho Municipal de Educação; 2002. p. 31-6.

22. Westphal MF, Ziglio E. Políticas públicas e investimentos: a intersetorialidade. In: Fundação Prefeito Faria Lima-Cepam, organizador. O município no século XXI: cenários e perspectivas. São Paulo: Fundação Prefeito Faria Lima-Cepam; 1999. p. 111-21.

23. Ministério de Educação e Cultura. Parâmetros Curriculares Nacionais (PCN) - temas transversais. 5ạ e 8a séries. Brasília: Departamento de Política da Educação Fundamental, Secretaria de Educação Fundamental, Ministério de Educação e Cultura; 1998.

Recebido em 05/Fev/2003

Versão final reapresentada em 12/Jan/2004 Aprovado em 11/Mar/2004 